\title{
Avaliação do Consumo de Água em Canteiros de Obra da Região Metropolitana do Recife
}

\author{
Costa Filho. E, \\ Escola Politécnica de Pernambuco \\ Universidade de Pernambuco \\ 50.720-001 - Recife, Brasil \\ edsoncosta.egn@gmail.com
}

\author{
Silva, R. S. \\ Escola Politécnica de Pernambuco \\ Universidade de Pernambuco \\ 50.720-001 - Recife, Brasil \\ simonerosa@poli.br
}

Resumo O setor da construção civil consome grande volumes de água potável das cidades. Este artigo objetiva apresentar indicadores sobre o consumo de água em canteiros de obra da Região Metropolitana do Recife, realizar as devidas interpretações desses números e propor medidas para reduzir o consumo. Analisaram-se os seguintes indicadores: Quantidade de funcionários e consumo de água mensal as obras, relação entre custo total mensal gasto com a água pelas obras e funcionários, consumo diário de água para fins pessoais dos funcionários. Foram selecionados 2 canteiros de obra da Moura Dubeux Engenharia(MD Engenharia), observando as atividades de consumo de água, bem como possiveis focos de desperdicio e medidas de reúso, além das medições setorizadas das instalações hidrossanitárias. Os resultados mostram que o consumo dos trabalhadores apresenta variações no tempo, devido a demanda de água utilizada para produção. Mesmo assim, medidas redutoras devem ser aplicadas para contribuir com o meio ambiente.

\footnotetext{
Abstract The civil construction industry consumes large volumes of drinking water of cities. This article aims to present indicators on water consumption in construction sites in the metropolitan region of Recife, perform the appropriate interpretations of these numbers and propose measures to reduce consumption. They analyzed the following indicators: amount of employees and monthly water consumption the works, relationship between monthly total cost spent on the water by the works and staff, daily consumption of water for personal purposes. 2 construction sites were selected from the Moura Dubeux Engenharia (MD engineering), observing the activities of water consumption, as well as possible sources of waste and reuse measures, in addition to the specialized measurements plumbing plants. The results show that the consumption of workers presents variations in time, due to demand for water used for production. Even so, reducing measures must be applied in order to contribute to the environment.
} 


\section{Introdução}

A ONU desenvolveu uma série de encontros sobre o tema da escassez de água. O primeiro deles foi a Conferência das Nações Unidas para a Água (1977). Posteriormente, a Década Internacional de Abastecimento da Água Potável e Saneamento (1981-1990) e a Conferência Internacional sobre Água e Meio Ambiente (1992) e a Cúpula da Terra (1992). Todos eles desencadearam uma busca por soluções, por parte dos grandes setores industriais, para o problema do descaso com a água.

O Conselho Brasileiro de Construção Sustentável CBCS, afirma que o setor da construção civil consume boa parte da água potável no mundo, sendo que em áreas urbanizadas o consumo é de cerca de $50 \%$ da água potável fornecida à região. A substituição do uso da água potável por fontes alternativas adequadas poderá diminuir esse valor para algo entre 30 a $40 \%$, segundo o CBCS. A cidade do Recife não está isenta dessa estatística.

Assim, esse artigo objetiva discutir, de modo geral, a questão do consumo de água nas obras, baseando-se em indicadores das obras e relatório de monitoramento, além de contribuir com a divulgação de políticas de conservação e uso consciente da água em centros urbanos, especificamente, com a conscientização da sociedade com relação à utilização racional da água.

\section{Metodologia}

Com a realização de pesquisa bibliográfica, selecionaram-se algumas construções verticais em processo de execução da MD Engenharia, empresa atuante na construção de condomínios e edifícios de luxo no Nordeste.

\subsection{Seleção de obras}

2 canteiros de obras foram escolhidos para monitoramento mensal do consumo de água pelos funcionários. Essas obras apresentaram as melhores condições para a instalação dos equipamentos de medição. Ambas as obras são construções de prédios residenciais, cujos nomes são: João Heráclio e Porto Ravena.

\subsection{Mananciais de abastecimento de água}

Para as obras estudadas, percebe-se que a obra João Heráclio utiliza água proveniente de caminhão-pipa e COMPESA (Companhia Pernambucana de Saneamento Concessionária de Água de Pernambuco). Já a obra Porto Ravena obtém água somente através de caminhão-pipa.

\subsection{Uso e Armazenamento de água nas obras}

A água adquirida é guardada em caixas d'águas, cujos volumes dependem da finalidade da provável utilização da água. Nas obras, a água destinada as atividades higiênicas funcionários está locada em reservatórios específicos. O restante da água está guardado para as atividades de consumo destinadas a produção.

A água é usada em quase todos os serviços de engenharia, às vezes como componente e outras como ferramenta. Entra como componente nos concretos e argamassas, e na compactação dos aterros e como ferramenta nos trabalhos de limpeza, resfriamento e cura do concreto (NETO, 2005).

A Norma Regulamentadora do Ministério do Trabalho, a NR - 18 citam os itens básicos para o trabalhador desenvolver suas atividades profissionais e quantifica o número mínimo de equipamentos por número de funcionários, sendo que, refeitórios, instalações hidrossanitárias e bebedouros estão relacionados com o uso de água nos canteiros. No refeitório há a presença de lavatório para as mãos, cozinha, etc.. As instalações hidrossanitárias compõem os vestiários e banheiros, onde os funcionários realizam suas atividades pessoais. Os bebedouros ficam em alguns pontos da obra, para que os trabalhadores tenham acesso à água para beber.

\subsection{Reúso e desperdício de Água}

Na obra João Heráclio, identificou-se uma medida simples, mas que contribui com a missão de reutilizar e poupar água: o reaproveitamento da água utilizada no lavatório para o mictório. As figuras 01 e 02 mostram isso. Esse mecanismo consiste em direcionar a água que cai no assoalho da pia para um local onde existe uma encanação, que irá escoar a água para o local do mictório. Embora seja em pequena dimensão, essa medida mostra que é possível realizar iniciativas criativas para contribuir a implantação de conceitos e modelos de utilização sustentável dos recursos hídricos. A obra Porto Ravena não possui essa medida. 


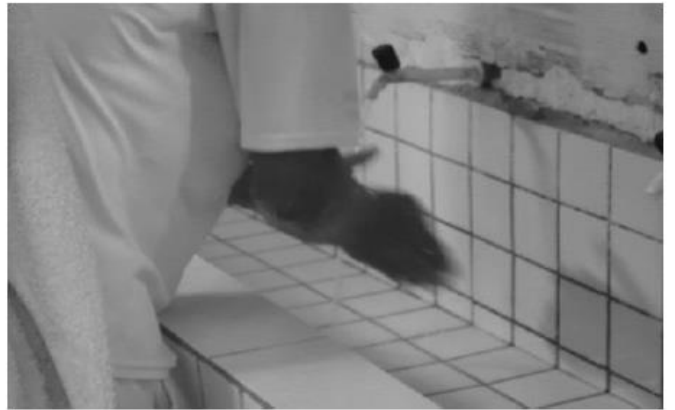

Figura 01 - Trabalhador lavando as mãos no João Heráclio.

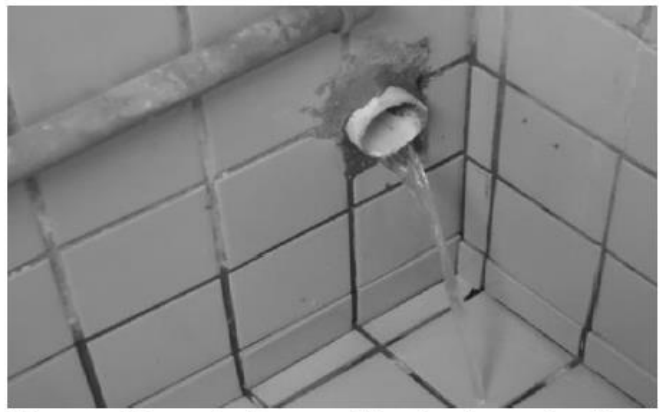

Figura 02 - A água utilizada é conduzida para o mictório. João Heráclio.

Além disso, há presença de cartazes informativos com instruções para os trabalhadores com relação a alertas e instruções sobre o uso da água. Isso são medidas que visam envolver o funcionário nos temas ambientais, tentando mostrar a importância de utilizar a água com sabedoria. As figuras 03 e 04 testificam essa informação.

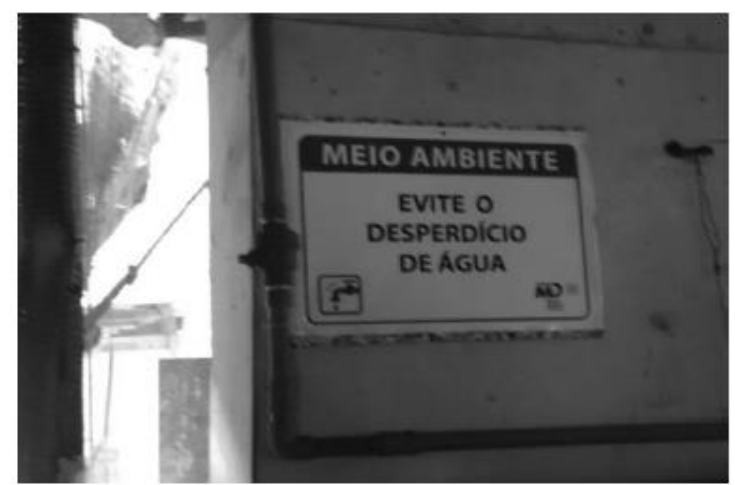

Figura 03 - Cartazes de alerta no Porto Ravena.

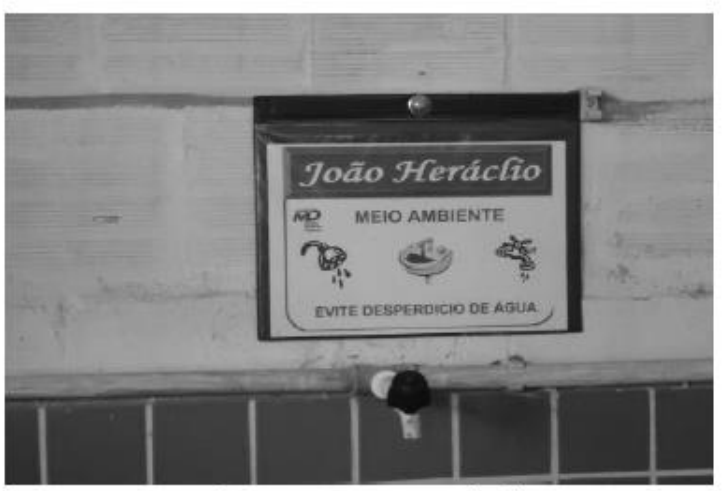

Figura 04 - Alerta no João Heráclio.

\subsection{Obtenções dos dados das obras}

Os dados para realização da pesquisa foram obtidos em consultas ao setor do almoxarifado e escritório de engenharia das obras. As medições setorizadas foram realizadas nas redondezas do setor de vestiário, contabilizando apenas o volume gasto com higiene pessoal dos funcionários, excluindo assim, a quantidade de água usada para bebedouros, cozinha, etc.

\subsection{Cálculos dos indicadores}

Os indicadores a utilizados na pesquisa foram:

a) Quantitativo de funcionário mensal;

b) Volume de água consumido mensal pela obra;

c) Volume de água consumido pelos funcionários mensalmente;

d) Volume consumido por funcionário por dia;

e) Relação entre a quantidade consumida de água, na obra e pelos trabalhadores;

O gráfico 01 mostra os quantitativos mensais dos funcionários nas obras Porto Ravena e João Heráclio. 


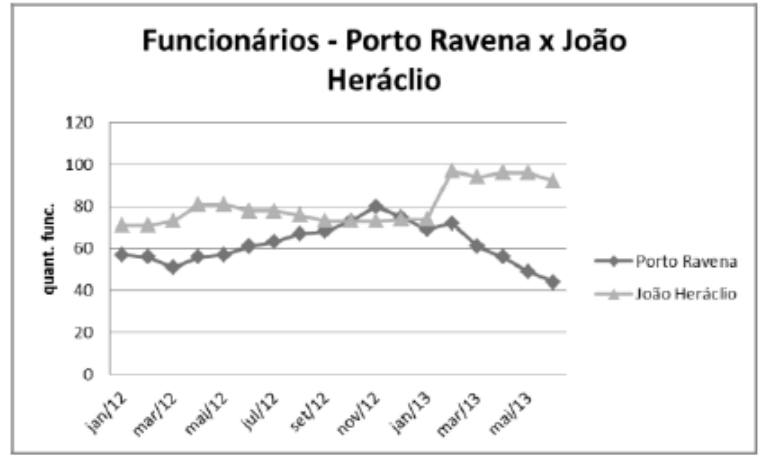

Gráfico 01 - quantitativos de funcionários mensal das obras.

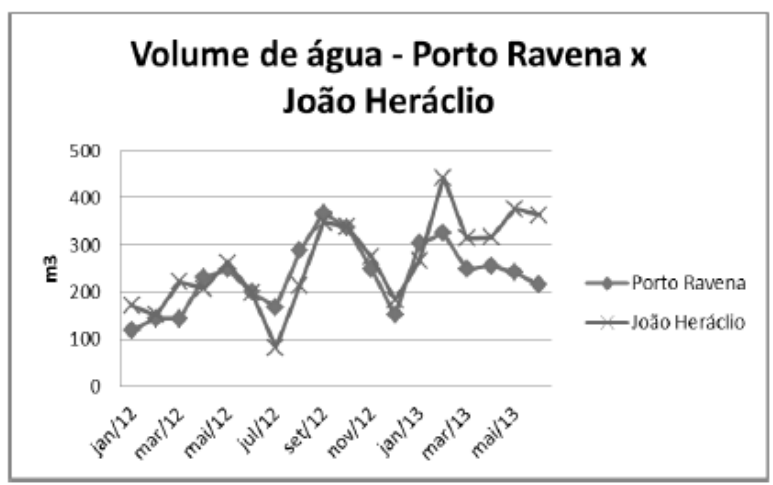

Gráfico 02 - Volume mensal consumido pelas obras.

Os volumes de água consumidos mensalmente pelos funcionários foram obtidos através das leituras realizadas nos hidrômetros. As tabelas 01 e 02 mostram as medições realizadas e seus respectivos valores para, respectivamente, Porto Ravena e João Heráclio.

Tabela 01 - Consumo dos funcionários no Porto Ravena.

\begin{tabular}{|c|c|c|}
\hline Medições & Data & Valores $\left(\mathrm{m}^{3}\right)$ \\
\hline $1^{\circ}$ MEDIÇÃO: & $07 / 01 / 2013$ & 249 \\
\hline $2^{\circ}$ MEDIÇÃO: & $07 / 02 / 2013$ & 149 \\
\hline $3^{\circ}$ MEDIÇÃO: & $08 / 03 / 2013$ & 48 \\
\hline $4^{\circ}$ MEDIÇÃO: & $08 / 04 / 2013$ & - \\
\hline $5^{\circ} \mathrm{MEDIÇÃO:}$ & $07 / 05 / 2013$ & 117 \\
\hline $6^{\circ}$ MEDIÇÃO: & $07 / 06 / 2013$ & 170 \\
\hline $7^{\circ} \mathrm{MEDIÇÃO:}$ & $08 / 07 / 2013$ & 192 \\
\hline $8^{\circ}$ MEDIÇÃO: & $07 / 08 / 2013$ & 172 \\
\hline
\end{tabular}

Tabela 02 - Consumo dos funcionários no João Heráclio.

\begin{tabular}{|c|c|c|}
\hline Medições & Data & $\begin{array}{c}\text { Valores } \\
\left(\mathrm{m}^{3}\right)\end{array}$ \\
\hline $1^{\circ}$ MEDIÇÃO: & $15 / 02 / 2013$ & 140 \\
\hline $2^{\circ}$ MEDIÇÃO: & $15 / 03 / 2013$ & 128 \\
\hline $3^{\circ}$ MEDIÇÃO: & $15 / 04 / 2013$ & 118 \\
\hline $4^{\circ}$ MEDIÇÃO: & $15 / 05 / 2013$ & 90 \\
\hline $5^{\circ}$ MEDIÇÃO: & $14 / 06 / 2013$ & 99 \\
\hline $6^{\circ}$ MEDIÇÃO: & $17 / 07 / 2013$ & - \\
\hline $7^{\circ} \mathrm{MEDIÇÃO}$ & $15 / 08 / 2013$ & 34 \\
\hline
\end{tabular}

A expressão que define o consumo de um funcionário por dia é expresso por:

cosumo. diario $=\frac{\text { consumo }}{20}$

, onde Consumo.diario $=$ Consumo de um funcionário por dia;

Consumo $=$ Medições realizadas no mês considerado; 20 = número de dias úteis de trabalho em 1 mês;

A tabela 03 informa uma análise estatística-descritiva dos valores obtidos.

Tabela 03 - Estatística-descritiva do volume de água

Estatística descritiva - Volume de água, em litros, por dia, consumido por 1 funcionário

\begin{tabular}{|c|c|c|c|c|c|}
\hline Obras & Média & $\begin{array}{c}\text { Desvio } \\
- \\
\text { Padrão }\end{array}$ & $\begin{array}{c}\text { Coef. de } \\
\text { variação }\end{array}$ & $\begin{array}{c}\text { Media } \\
\text { na }\end{array}$ & $\begin{array}{c}\text { Variân } \\
\text { cia }\end{array}$ \\
\hline $\begin{array}{c}\text { Porto } \\
\text { Ravena }\end{array}$ & 92,17 & 26,05 & 0,2827 & 101 & 678,74 \\
\hline $\begin{array}{c}\text { João } \\
\text { Herácli } \\
\text { o }\end{array}$ & 89,00 & 43,60 & 0,4899 & 92 & $\begin{array}{c}1901,3 \\
3\end{array}$ \\
\hline
\end{tabular}

A relação entre o volume de água consumido pela obra e pelos trabalhadores pode ser obtida através da expressão:

cosumo. diario $=\frac{\text { consumo }}{20}$ 
onde:

$\mathrm{C}=$ consumo de trabalhadores por consumo da obra;

Vol.total.mensal $=$ volume gasto na obra no mês considerado;

A tabela 04 mostra esses valores.

Tabela 04 - Relação de consumo entre funcionários e obra

\begin{tabular}{|l|r|r|r|r|r|r|}
\hline \multicolumn{7}{|c|}{ Relação entre o consumo de água dos funcionários e da } \\
obra em geral \\
\hline \multirow{2}{*}{ Obras } & jan & fev & mar & abr & mai & jun \\
\cline { 2 - 7 } & & & & & & \\
\hline $\begin{array}{l}\text { Porto } \\
\text { Ravena }\end{array}$ & $* * * *$ & 0,429 & 0,516 & 0,461 & 0,372 & 0,458 \\
\hline $\begin{array}{l}\text { João } \\
\text { Heráclio }\end{array}$ & 0,935 & 0,336 & 0,153 & $* * * * *$ & 0,310 & 0,467 \\
\hline
\end{tabular}

\subsection{Medidas para redução do consumo}

ANA (2005) propõe medidas que podem ser aplicadas nos canteiros de obra para monitoramento do consumo, junto com medidas educativas e uso de fontes alternativas.

A instalação de um sistema de gestão de água, munido de um monitoramento do consumo a partir da instalação de hidrômetros para as áreas de uso doméstico de água, como as áreas de ambientes sanitários, refeitórios, constituem uma grande oportunidade para reduzir, através do controle, os gastos com água pelos funcionários.

Para se utilizar fontes alternativas, é necessário fornecer uma água cujos padrões estejam de acordo com as especificações das atividades que se destinam, a fim de garantir a qualidade das construções, bem como a saúde e segurança dos funcionários.

A utilização de modelos de equipamentos economizadores representa um ganho na implantação de medidas poupadoras de água. Porém, se faz necessário estudar a viabilidade econômica da do uso destes equipamentos, pois por ser uma estrutura temporária, o canteiro de obras não se mostra o local mais adequado para se utilizar produtos mais requintados.

\subsection{Tecnologias}

Segue abaixo algumas tecnologias que podem ser exploradas em canteiros de obras. a) Arejador: é um dispositivo fixado na saída da torneira, para reduzir a passagem da água. Os arejadores diminuem cerca de $50 \%$ o jato das torneiras, resultando em vazões entre 0,13 1/s e 0,76 $1 / \mathrm{s}$.

b) Pulverizador: é um dispositivo que transforma o jato de água em um feixe de pequenos jatos semelhante a um chuveirinho. Os pulverizadores reduzem a vazão para valores entre $0,06 \mathrm{l} / \mathrm{s}$ a 0,12 $1 / \mathrm{s}$, podendo chegar até a $0,031 / \mathrm{s}$.

c) Prolongador: prolongamentos, desde que bem projetados, também podem representar economia de água, aproximando e direcionando melhor o jato ao objeto a ser lavado.

d) Válvula para mictórios: reduz aproximadamente $60 \%$ o consumo comparado com descarga contínuas de $0,051 / \mathrm{s}$.

e) Bacia com caixa de volume reduzido: redução para 6 litros ou acionamento seletivo que permitem a regulagem de 3 ou 6 litros por acionamento.

f) Gatilhos de pontas para mangueiras: a adoção de bicos tipo gatilho nas pontas de mangueiras elimina os períodos de ociosidade no uso. Por exemplo: a limpeza de fôrmas por um período de 30 minutos, com uma torneira medianamente aberta, pode consumir algo em torno de 216 litros de água e até 560 litros se estiver totalmente aberta.

g) Emprego de sacos de tecidos ou bidim no processo da cura do concreto: sendo o processo de cura do concreto uma atividade que gera elevado consumo de água, no caso estudado constatou-se o uso de 160 a 200 litros de água por $\mathrm{m}^{3}$ de concreto, o emprego de sacos de tecidos ou de qualquer outro material que retenha certo volume de água, pode proporcionar economia de consumo devido à menor necessidade de ciclos de molhagem.

\section{Discussão dos resultados}

Baseado nas visitas realizadas, percebe-se claramente que a ação de medidas educativas, como colocação de cartazes e realização de palestras para os funcionários é importante, mas que, sozinha, não conseguirá atuar de forma marcante para reduzir consideravelmente o consumo de água pelos funcionários. Isso é evidente por que não, mesmo com os cartazes e treinamento, os índices de consumo mostram que a média de consumo diário de cada 
funcionário ainda é superior ao que a OMS recomenda como mínimo aceitável.

Pelo coeficiente de variação, vemos que o quantitativo de funcionários, para o Porto Ravena variou próximo da variação do volume de água consumido por funcionário por dia. Os trabalhadores dessa obra apresentam, pelo menos nesses meses de monitoramento, um padrão de consumo de água. Já para o João Heráclio. Essa comparação indica uma disparidade grande entre a quantidade de consumidores e o volume consumido. Isso evidencia que nessa obra, praticamente o mesmo número de funcionários apresentam um padrão de consumo aleatório. Mesmo assim, a média de consumo é menor no João Heráclio, que no Porto Ravena, muito em função da $3^{\circ}$ medição.

Tento em vista a necessidade de obter mais informações sobre essas medições setorizadas, não só nas areas de vestiário, mas também no setor de cozinha, bebedouros, a instalação de mais hidrômetros em outras obras se faz necessário. Haverá um enorme ganho de material para análise e, com isso, a representatividade qualitativa da pesquisa aumentará.

\section{Agradecimentos}

Agradecemos a Escola Politécnica de Pernambuco, pelo financiamento do projeto, aliado a parceria com a Moura Dubeux Engenharia, que propiciou a instalação dos hidrômetros e consequente monitoramento e coleta de dados.

\section{Referências}

[1] ANA, COMASP, FIESP, MINISTÉRIO DO MEIO AMBIENTE E SINDUSCON SP. Manual Técnico de Uso e Conservação e Reuso da Água em Residenciais. São Paulo, Junho 2005.

[2] CBCS. Conselho Brasileiro de Construção Sustentável. Comitê Temático da Água. Aproveitamento de fontes alternativas de água em edifícios. Acesso em: 08 mai. 2013. Disponível em: < http://www.cbcs.org.br >

[3] MINISTÉRIO DO TRABALHO. Norma Regulamentadora $\mathrm{n}^{\circ} 18$ - NR 18

[4] Condições e Meio Ambiente de Trabalho na Indústria da Construção. Disponível em $<\mathrm{http}: / /$ www.mte.gov.br/legislacao/>. Acesso em 08 de Abril de 2013.

[5] NETO, A. F.; Água como Material de Construção. Cuiabá. Disponível em: $<$ http://www.forumdaconstrucao.com.br/conteudo. php? $\mathrm{a}=43 \& \operatorname{Cod}=625>$. Acesso em 08 de Abril de 2013.

[6] ORGANIZAÇÃO DAS NAÇÕES UNIDAS NO BRASIL. A ONU e a água. 2012. Disponível em: $<$ http://www.onu.org.br/a-onu-em-acao/a-onuem-acao/a-onu-e-a-agua/ $>$. Acesso em: 04/05/2013.

[7] PESSARELLO, R.G.; Estudo Exploratório quanto ao Consumo de água na produção de obras de edifícios: Avaliação e Fatores influenciadores. São Paulo, Fev. 2008.

[8] REDAÇÃO ACEWEB. Os verdadeiros impactos da construção civil. 2010. Disponível em: $<$ http://www.aecweb.com.br/aec-news/materia/2206/os-impactos-da-construcao-civil.html>. Acesso em: 04/05/2013.

[9] REVISTA SUSTENTABILIDADE. Consumo de água nos canteiros, 24 mar. 2008. Disponível em: $<$ http://revistasustentabilidade.com.br/consumode-agua-nos-canteiros/ > Acesso em: 18 mar. 2013. 